\title{
Risk Factors of Type 1 Leprosy Reaction in Leprosy Patients attending Leprosy Division of Dermatology and Venereology Outpatient Clinic of Dr Soetomo General Hospital in 2017-2019: A Retrospective Study
}

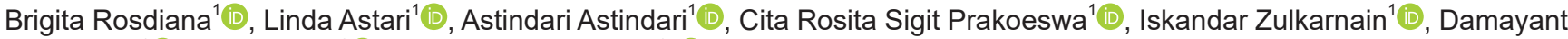 \\ Damayanti $^{1}$, Budi Utomo ${ }^{2}$ D, M. Yulianto Listiawan ${ }^{1 *}$ (D) \\ ${ }^{1}$ Department of Dermatology and Venereology, Universitas Airlangga, Dr. Soetomo General Academic Teaching Hospital, \\ Universitas Airlangga Teaching Hospital, Surabaya, Indonesia; ${ }^{2}$ Department of Public Health Sciences, Faculty of Medicine, \\ Universitas Airlangga, Surabaya, Indonesia
}

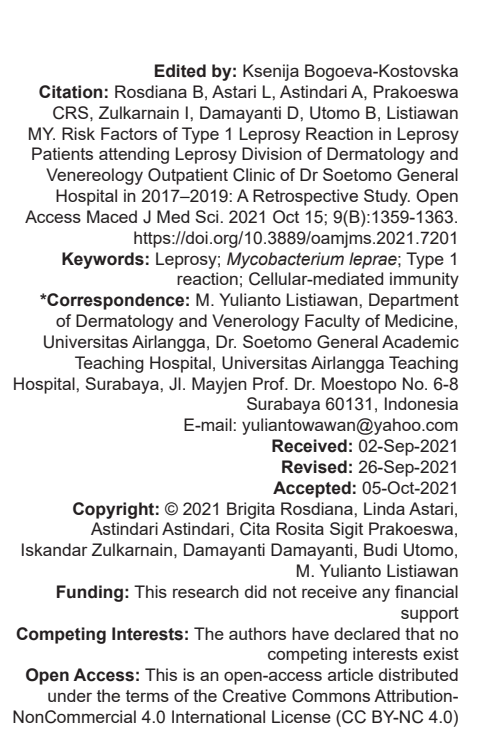

\section{Abstract}

BACKGROUND: Type 1 leprosy reaction is a delayed hypersensitivity reaction caused by increased response of cellular-mediated immunity to Mycobacterium leprae. Manifestations include skin and nerve lesions, edema, and permanent disabilities. There are several risk factors that should be recognized to prevent disabilities.

AIM: The aim of this study was to analyze the relationship of risk factors to the occurrence of type 1 leprosy reaction in leprosy patients treated at the Outpatient Clinic of Dr. Soetomo General Hospital.

METHODS: This study was an analytical study with retrospective observational study design. Data were secondary from the medical records of leprosy patients at the Outpatient Clinic of Dr. Soetomo General Hospital from January 2017 to December 2019

RESULTS: Out of 364 patients in the Outpatient Clinic, 190 (52.2\%) had leprosy without a reaction and $65(17.9 \%)$ had type 1 reaction. Analysis showed that age, leprosy type, and treatment regimen were significantly associated with the incidence of type 1 reaction ( $p=0.023 ; 0.003$ and 0.004 , respectively), with the leprosy type as the most dominant risk factor. Age 15-34 years old; leprosy types BB, BL, and BT; and the MB MDTL therapeutic regimen are risk factors for the occurrence of type I leprosy reaction.

CONCLUSION: There is a statistically significant correlation between the risk factor and the occurrence of type 1 leprosy reaction in leprosy patient. The risk factor that has significant correlation is age 15-34 years; leprosy types $\mathrm{BB}, \mathrm{BL}$, and BT; and the MB MDTL therapeutic regimen. The most significant risk factor for the occurrence of type 1 leprosy reaction from our study is the type of leprosy (BB, BL, and BT).

\section{Introduction}

Type 1 leprosy reaction is a delayed hypersensitivity reaction caused by an increase in cellular immunity response to Mycobacterium leprae antigen on the skin and nerves of leprosy patients [1].

Clinical manifestations of type 1 reaction are inflammation of the skin and nerves that can cause skin lesions, nerve lesions, edema, and permanent disability [2], [3]. Indonesia ranks $3^{\text {rd }}$ with the highest number of the leprosy patients in the world. In 2017, the Indonesian Ministry of Health reported that the incidence of leprosy in Indonesia is 6.08 new cases per 100,000 population, with East Java as the area with the highest prevalence of leprosy [4]. Leprosy treatment has been developed around the world to eradicate this disease, but along the way there has been some reactions arising from leprosy treatment, one of which is type 1 leprosy reaction. The incidence of type 1 reactions varies in various countries, namely around $19.7-30 \%$ [3], [5], [6]. The worst prognosis that arises due to type 1 leprosy reactions is disability, and the estimated number of disabilities due to leprosy reactions is still quite high [2].

\section{Aim}

The aim of the study is to analyze the relationship of risk factors to the occurrence of type 1 leprosy reaction in leprosy patients treated at the Outpatient Clinic of Dr. Soetomo General Hospital. Study the use of using private funds. 


\section{Materials and Methods}

This study was an analytical study, with retrospective observational study design, to analyze the relationship of risk factors to the occurrence of type 1 leprosy reactions in leprosy patients, especially in patients who are treated at the Leprosy Division of Dermatology and Venerology Outpatient Clinic of Dr. Soetomo General Hospital in 2017-2019, using secondary data in the form of medical record.

The inclusions criteria were all of the patients recorded in medical records with a diagnosis of type 1 leprosy reaction in leprosy patient at the Leprosy Division of Dermatology and Venerology Outpatient Clinic of Dr. Soetomo General Hospital from January 2017 to December 2019. Exclusion criteria were incomplete medical records and leprosy patients with type 2 leprosy reaction. Those data were input into a data collection sheet to be analyzed using the Statistical Package for Social Sciences (SPSS) version 17.

\section{Results}

The number of cases that met the inclusion criteria showed the incidence of leprosy in Dr. Soetomo General Hospital from January 2017 to December 2019 was 364 cases. (Table 1) showed the demographic distribution in those 364 cases with $52.2 \%$ (190 cases) had leprosy without a reaction and $17.9 \%$ (65 cases) experienced type 1 reactions.

Table 1: Distribution of type 1 leprosy reactions in patients attended Dr. Soetomo General Hospital from January 2017 to December 2019

\begin{tabular}{lllll}
\hline Patients category & Year & \multicolumn{2}{l}{ Total (\%) } \\
\cline { 2 - 4 } & $2017(\%)$ & $2018(\%)$ & $2019(\%)$ & \\
\hline Leprosy division & $135(37.1)$ & $125(34.3)$ & $104(28.6)$ & $364(100)$ \\
Leprosy without a reaction & $70(19.2)$ & $70(19.2)$ & $50(13.7)$ & $190(52.2)$ \\
Leprosy with type 1 reaction & $26(7.14)$ & $18(4.9)$ & $21(5.8)$ & $65(17.9)$ \\
\hline
\end{tabular}

On the other hand, (Table 2) showed the age distribution in leprosy patients with type 1 reaction in Dr. Soetomo General Hospital from January 2017 to December 2019. The results showed that the age range 35-55 years had the highest prevalence with $56.9 \%$ (37 patients).

Table 2: Age distribution in type 1 leprosy reaction patients in Dr. Soetomo General Hospital from January 2017 to December 2019

\begin{tabular}{lllll}
\hline Age (year) & Year & & & Total (\%) \\
\cline { 2 - 4 } & $2017(\%)$ & $2018(\%)$ & $2019(\%)$ & \\
\hline$<15$ & $0(0)$ & $1(1.5)$ & $0(0)$ & $1(1.5)$ \\
$15-34$ & $8(12.3)$ & $4(6.2)$ & $7(10.8)$ & $19(29.2)$ \\
$35-55$ & $15(23.1)$ & $10(15.4)$ & $12(18.5)$ & $37(56.9)$ \\
$>55$ & $3(4.6)$ & $3(4.6)$ & $2(3.1)$ & $8(12.3)$ \\
Total & $26(40.0)$ & $18(27.7)$ & $21(32.3)$ & $65(100)$ \\
\hline
\end{tabular}

Moreover, (Table 3) showed the gender distribution in leprosy patients with type 1 reaction in Dr. Soetomo General Hospital from January 2017 to December 2019. The results showed that male patients had the highest prevalence with $75.4 \%$ (49 patients).

Table 3: Gender distribution in type 1 leprosy reaction patients in Dr. Soetomo General Hospital from January 2017 to December 2019

\begin{tabular}{lllll}
\hline Gender & Year & & & Total (\%) \\
\cline { 2 - 4 } & $2017(\%)$ & $2018(\%)$ & $2019(\%)$ & \\
\hline Male & $21(32.2)$ & $12(18.5)$ & $16(24.6)$ & $49(75.4)$ \\
Female & $5(7.7)$ & $6(9.2)$ & $5(7.7)$ & $16(24.6)$ \\
Total & $26(40.0)$ & $18(27.7)$ & $21(32.3)$ & $65(100)$ \\
\hline
\end{tabular}

Furthermore, (Table 4) showed the nutritional status in leprosy patients with type 1 reaction in Dr. Soetomo General Hospital from January 2017 to December 2019. The results showed that patients with good nutritional status had the highest prevalence with 98.5\% (64 patients).

Table 4: Nutritional status distribution in type 1 leprosy reaction patients in Dr. Soetomo General Hospital from January 2017 to December 2019

\begin{tabular}{lllll}
\hline Nutritional status & Year & & & Total (\%) \\
\cline { 2 - 4 } & $2017(\%)$ & $2018(\%)$ & $2019(\%)$ & \\
\hline Under & $1(1.5)$ & $0(0)$ & $0(0)$ & $1(1.5)$ \\
Normal & $25(38.5)$ & $18(27.7)$ & $21(32.3)$ & $64(98.5)$ \\
Over & $0(0 \%)$ & $0(0 \%)$ & $0(0 \%)$ & $0(0 \%)$ \\
Total & $26(40.0)$ & $18(27.7)$ & $21(32.3)$ & $65(100)$ \\
\hline
\end{tabular}

Table 5 showed the bacterial index status in leprosy patients with type 1 reaction in Dr. Soetomo General Hospital from January 2017 to December 2019. The results showed that patients with negative bacterial index had the highest prevalence with $72.3 \%$ (47 patients).

Table 5: Bacterial index distribution in type 1 leprosy reaction patients in Dr. Soetomo General Hospital from January 2017 to December 2019

\begin{tabular}{lllll}
\hline Bacterial index & Year & & Total (\%) \\
\cline { 2 - 4 } & $2017(\%)$ & $2018(\%)$ & $2019(\%)$ & \\
\hline Negative & $19(29.2)$ & $12(18.5)$ & $16(24.6)$ & $47(72.3)$ \\
$1+$ & $3(4.6)$ & $1(1.5)$ & $4(6.2)$ & $8(12.3)$ \\
$2+$ & $4(6.2)$ & $4(6.2)$ & $1(1.5)$ & $9(13.8)$ \\
$3+$ & $0(0)$ & $1(1.5)$ & $0(0)$ & $1(1.5)$ \\
$4+$ & $0(0)$ & $0(0)$ & $0(0)$ & $0(0)$ \\
$>4+$ & $0(0)$ & $0(0)$ & $0(0)$ & $0(0)$ \\
Total & $26(40.0)$ & $18(27.7)$ & $21(32.3)$ & $65(100)$ \\
\hline
\end{tabular}

Table 6 showed the types of leprosy in leprosy patients with type 1 reaction in Dr. Soetomo General Hospital from January 2017 to December 2019. The results showed that the type of leprosy $\mathrm{BB}$ had highest prevalence with $61.6 \%$ (40 patients).

Table 6: Types of leprosy distribution in type 1 leprosy reaction patients in Dr. Soetomo General Hospital from January 2017 to December 2019

\begin{tabular}{lllll}
\hline Type of leprosy & Year & & Total (\%) \\
\cline { 2 - 3 } & $2017(\%)$ & $2018(\%)$ & $2019(\%)$ & \\
\hline TT (Tuberculoid leprosy) & $0(0)$ & $0(0)$ & $0(0)$ & $0(0)$ \\
BT (Borderline tuberculoid) & $0(0)$ & $0(0)$ & $0(0)$ & $0(0)$ \\
BB (Borderline lepromatous) & $12(18.5)$ & $13(20.0)$ & $15(23.1)$ & $40(61.6)$ \\
BL (Lepromatous leprosy) & $12(18.5)$ & $4(6.2)$ & $4(6.2)$ & $20(20.8)$ \\
LL (Lepromatous leprosy) & $2(3.1)$ & $1(1.5)$ & $2(3.1)$ & $5(7.7)$ \\
Neural & $0(0)$ & $0(0)$ & $0(0)$ & $0(0)$ \\
Total & $26(40.0)$ & $18(27.7)$ & $21(32.3)$ & $65(100)$ \\
\hline
\end{tabular}

Table 7 showed therapeutic regimens in leprosy patients with type 1 reaction in Dr. Soetomo General 
Hospital from January 2017 to December 2019. The results showed that $\mathrm{MB}$ was the therapeutic regimen with the highest prevalence at 100\% (65 patients).

Table 7: Therapeutic regimens distribution in type 1 leprosy reaction patients in Dr. Soetomo General Hospital from January 2017 to December 2019

\begin{tabular}{lllll}
\hline Therapeutic regimen & Year & & Total (\%) \\
\cline { 2 - 4 } & $2017(\%)$ & $2018(\%)$ & $2019(\%)$ & \\
\hline PB & $0(0)$ & $0(0)$ & $0(0)$ & $0(0)$ \\
MB & $26(40.0)$ & $18(27.7)$ & $21(32.3)$ & $65(100)$ \\
Total & $26(40.0)$ & $18(27.7)$ & $21(32.3)$ & $65(100)$ \\
\hline
\end{tabular}

Then from these variables, data were analyzed by bivariate and multivariate analysis. Table 8 showed the results of the bivariate analysis. The results of data analysis showed that age, type of leprosy and treatment regimen were significantly associated with the incidence of type 1 reactions ( $p=0.023 ; 0.003$ and 0.004 , respectively), with leprosy type as the most dominant risk factor. Gender, nutritional status and bacterial index were not significantly associated with the incidence of type 1 reactions in leprosy patients.

Table 8: Bivariate analysis results for type 1 leprosy reaction patients in Dr. Soetomo General Hospital from January 2017 to December 2019

\begin{tabular}{|c|c|c|c|c|}
\hline \multicolumn{5}{|l|}{ Bivariate analysis } \\
\hline \multirow[t]{2}{*}{ Variable } & \multicolumn{2}{|c|}{ Type 1 reaction (\%) } & \multirow[t]{2}{*}{$\chi^{2}$} & \multirow[t]{2}{*}{$\mathrm{p}$} \\
\hline & Yes & No & & \\
\hline Age (year) & & & 5.140 & 0.023 \\
\hline$<15$ & $1 / 65(1.5)$ & $11 / 190(5.8)$ & & \\
\hline $15-34$ & $19 / 65(29.2)$ & $86 / 190(45.3)$ & & \\
\hline $35-55$ & $37 / 65$ (56.9) & 69/190 (36.3) & & \\
\hline$>55$ & $8 / 65(12.3)$ & 24/190 (12.6) & & \\
\hline Gender & & & 0.564 & 0.453 \\
\hline Male & $49 / 65(75.4)$ & $134 / 65(70.5)$ & & \\
\hline Female & $16 / 65(24.6)$ & $56 / 65(29.5)$ & & \\
\hline Nutritional status & & & 0.052 & 0.819 \\
\hline Under & $1 / 65(1.5)$ & 7/190 (3.7) & & \\
\hline Normal & $64 / 65$ (98.5) & $183 / 190(96.3)$ & & \\
\hline Over & $0 / 65(0)$ & $0 / 190(0)$ & & \\
\hline Bacterial index & & & 1.421 & 0.233 \\
\hline Negative & $47 / 65(72.3)$ & $122 / 190(64.2)$ & & \\
\hline Positive & $18 / 65(26.7)$ & $68 / 190(35.8)$ & & \\
\hline Types of leprosy & & & 9.082 & 0.003 \\
\hline TT & $0 / 65(0)$ & $8 / 190(4.2)$ & & \\
\hline BT & $0 / 65(0)$ & $12 / 190(6.3)$ & & \\
\hline BB & $40 / 65(61.6)$ & 95/190 (50.0) & & \\
\hline $\mathrm{BL}$ & $20 / 65(20.8)$ & 33/190 (17.4) & & \\
\hline LL & $5 / 65(7.7)$ & $37 / 190(19.5)$ & & \\
\hline Neural & $0 / 65(0)$ & $3 / 190(1.6)$ & & \\
\hline Therapeutic regimen & & & 8.237 & 0.004 \\
\hline PB & $0 / 65(0)$ & $22 / 190(11.5)$ & & \\
\hline MB & $65 / 65(100)$ & $168 / 190(88.5)$ & & \\
\hline
\end{tabular}

Bivariate analysis was followed by multivariate analysis. The analysis began with a multivariate selection of candidate variables from the results of the previous bivariate analysis. Variable candidates pass the selection if the $p<0.25$. Table 9 showed the results of the initial multivariate analysis.

Table 9: Initial multivariate analysis results for type 1 leprosy reaction patients in Dr. Soetomo General Hospital from January 2017 to December 2019

\begin{tabular}{lll}
\hline Variable & $\mathrm{p}$-value & $\mathrm{OR}(95 \% \mathrm{Cl})$ \\
\hline Type of leprosy & 0.016 & $0.273(0.095-0.786)$ \\
Therapeutic regimen & 0.998 & $0.000(0.000)$ \\
Bacterial index & 0.309 & $0.707(0.362-1.380)$ \\
Age & 0.513 & $1.234(0.658-2.313)$ \\
\hline
\end{tabular}

Based on the initial multivariate analysis results, variables of therapeutic regimen, bacterial index, and age had a significance value $>0.05$, so these variables had to be excluded and reanalyzed. Table 10 showed the final multivariate analysis results.
Table 10: Final multivariate analysis results for type 1 leprosy reaction patients in Dr. Soetomo General Hospital from January 2017 to December 2019

\begin{tabular}{llll}
\hline Variable & B-value & p-value & OR $(95 \%$ Cl) \\
\hline Type of leprosy & -1.400 & 0.005 & $0.247(0.094-0.065)$ \\
Constant & 2.262 & 0.000 & \\
\hline
\end{tabular}

Based on the results of the final multivariate analysis, it showed that the variable, type of leprosy, has a significance value $<0.05(0.005)$, so it can be concluded that the non-borderline type of leprosy provides a protective effect against the incidence of skin reactions higher than the borderline type of leprosy. The protective effect can be measured using the probability formula:

$$
\begin{gathered}
\mathrm{y}_{\text {borderline }}=\mathrm{B}_{\text {constant }}+\mathrm{B}_{\text {leprosy type }} \\
\mathrm{y}_{\text {borderline }}=2.62+(-1.4)=1.22
\end{gathered}
$$

while

$\mathrm{y}_{\text {non-borderline }}=\mathrm{B}_{\text {constant }}+\mathrm{B}_{\text {leprosy type }}(2)$

$\mathrm{y}_{\text {non-borderline }}=2.62+(-1.4)(2)=-0.18$

thus,

$$
\begin{gathered}
\mathrm{P}_{\text {borderline }}=\frac{1}{1+e^{-y}}=\frac{1}{1+2.72^{-1.22}}=\frac{1}{1.3}=76.92 \% \\
\mathrm{P}_{\text {non-borderline }}=\frac{1}{1+e^{-y}}=\frac{1}{1+2.72^{-(-0.18)}}=\frac{1}{2.2}=45.45 \%
\end{gathered}
$$

It was found that the borderline leprosy type raises the risk of incidence of type 1 leprosy to $76.92 \%$ and the non-borderline type of leprosy raises the risk of incidence of type 1 leprosy to $45.45 \%$.

\section{Discussion}

Study conducted by Ranque et al. in 2007 supported these results, they found that $56.5 \%$ of patients aged more than 15 years experienced type 1 reactions with a significant analysis result (univariate $p<0.001$; multivariate $p=0.001$ ). They concluded that age is an independent risk factor for incidence of type 1 reactions with patients over 20 years of age are more likely to experience type 1 leprosy reactions. It can be said that age is an important risk factor in determining the incidence and severity of type 1 reaction [7].

There are two main reasons why type 1 leprosy reactions are more common at an older age. Type 1 leprosy reaction is mainly caused by high Th1 level. In children, the main immune response for reaction is Th2, while in older age group is Th1. This first reason may 
explain the lower frequency of type 1 leprosy reactions in children than in the older age group. The second reason is the high number of memory $T$ cells in adulthood. This in turn causes a secondary antigen cross reaction from Mycobacterium infection other than M. leprae; for example Mycobacterium tuberculosis. The crossreaction of the antigen triggered by Mycobacterium other than $M$. leprae can also cause type 1 reactions [7]. Increased cellular immune response that occurs in adulthood, namely by the entry of CD4 $+\mathrm{T}$ cells and the production of IL-1, TNF- $\alpha$, IL-2, and IFN- in lesions, and an increased Th1 response pattern known as the "inflam-aging," effectively causes an increase in the incidence of type I leprosy reactions [8].

The highest prevalence for gender was in males with $75.4 \%$ (49 patients), the study bivariate showed there's no significant correlation ( $p$ : 0,453$)$. Study conducted by Scollard et al. in 2015 supported these results. They found that sex has no significant relationship with the incidence of leprosy either without reaction or with a type 1 reaction [6]. Based on research conducted by Aisyah and Agusni in 2018 and Antunes et al., there was a predominance of leprosy in male patients. The reasons why there's a predominance of male leprosy patients might be related to stress. Stress is associated with immune responses and nonspecific responses to lymphocyte proliferation, the emergence of $T$ cells, specific antigens, activation of macrophages, changes in the balance of Th1 and Th2, and the release of cytokines such as IL-6s [6], [9]. All of those reasons could then trigger type 1 leprosy reaction [10].

The highest prevalence for nutritional status is normal with $98.5 \%$ (64 patients); the study bivariate showed there's no significant correlation (p: 0.819). These results were contradictory with study conducted by Rao and John in 2012. They found that there's a significant difference between the number of under-nutrition patients (body mass index< 18.5) in leprosy patients compared to non-leprosy patients $(p=0.0001)$ [11]. This discrepancy is influenced by lack of research related to data collection on nutritional status in the outpatient installation of Dr. Soetomo Surabaya. Data related to nutritional status come from measurements of patient's height and weight; however, there are incomplete data on body weight and height in medical records. The reason why nutritional value could be a risk factor for type 1 leprosy reaction is that lack of nutrients can lead to damage of body's defenses and results in immune suppression. Several micronutrients are important in maintaining the body's defenses and immune function such as immune response and antibody production [12].

The highest prevalence for bacterial index is negative with $72.3 \%$ (47 patients); the study bivariate showed that there's no significant correlation $(p=0.233)$. These results were contradictory with study conducted by others [7], [13], [14], [15], [16], [17].
Most of the studies found that patients with positive bacterial index have a higher chance of developing type 1 leprosy reaction than patients with negative bacterial index [7], [13], [14], [15], [16], [17]. This discrepancy could be because the low number of data. For example, Antunes in 2013 used 440 cases with 211 cases of type 1 leprosy reaction, while Hungria in 2016 used 753 cases with 418 cases of type 1 leprosy reaction. The highest prevalence for type of leprosy was for BB with $61.6 \%$ (40 patients); the study bivariate showed there's a significant correlation ( $p=0.003$ ). Study conducted by Antunes et al. in 2013 supported these results; they found that $68.5 \%$ of the samples who experienced reactions had borderline type of leprosy. Research by Hungria et al. in 2016 also found similar results; they found that $98.5 \%$ of the sample had borderline type of leprosy. Leprosy types BT, BB, and BL were the types of leprosy that experienced the most type 1 reactions [14], [15]. The tendency of borderline type leprosy patients to experience type 1 reactions may occur because the borderline type has very unstable immunity, so that when the level of bacteria increases, it will stimulate the phenomenon of cell-mediated hypersensitivity [18].

The highest prevalence for therapeutic regimen is $\mathrm{MB}$ with $100 \%$ (65 patients); the study bivariate showed that there's a significant correlation ( $p=0.004)$. Study conducted by Hungria et al. in 2016 supported these results; they found that MB patients had a higher tendency to develop leprosy reactions. Several other studies have also shown that leprosy reactions mainly occur in patients receiving $M B$ therapy [15], [19]. Type 1 leprosy reaction is related to the success of therapy in the MB therapeutic regimen, because the antigen from bacterial degradation will stimulate the body to produce antibodies and generate cell-mediated immune (CMI) response [20], [21]. The CMI that appears will cause an inflammatory reaction to the skin and nerves, which eventually arises as a type 1 leprosy reaction [20].

\section{Conclusion}

There is a statistically significant correlation between the risk factor and the occurrence of type 1 leprosy reaction in leprosy patient who are treated at the Leprosy Division of Dermatology and Venerology Outpatient Clinic of Dr. Soetomo General Hospital. The risk factor that has significant correlation is age 15-34 years; leprosy types BB, BL, and BT; and the MB MDTL therapeutic regimen. The most significant risk factor for the occurrence of type 1 leprosy reaction from our study is the type of leprosy (BB, BL, and BT). 


\section{Acknowledgment}

We would like to thank the patients who agreed to take part in the study and all medical staff in Dr. Soetomo General Hospital who helped in conducting this study.

\section{References}

1. Kar HK, Kumar B. IAL Textbook of Leprosy. New Delhi: Jaypee Brothers Medical Publishers; 2010.

2. da Nery JA, Filho FB, Quintanilha J, Machado AM, de Oliveira SS, Sales AM. Understanding the Type 1 reactional state for early diagnosis and treatment: A way to avoid disability in leprosy. An Bras Dermatol. 2013;88(5):787-92. http://doi. org/10.1590/abd1806-4841.20132004

\section{PMid:24173185}

3. Suchonwanit $\mathrm{P}$, Triamchaisri $\mathrm{S}$, Wittayakornrerk $\mathrm{S}$ Rattanakaemakorn P. Leprosy reaction in Thai population: A 20-year retrospective study. Dermatol Res Pract. 2015;2015:253154. http://doi.org/10.1155/2015/253154 PMid:26508912

4. World Health Organization. Santé WHO O Mondiale de la. Global Leprosy Update, 2018: Moving towards a Leprosy-free World Situation de la Lèpre dans le Monde, 2018: Parvenir à un Monde Exempt de lèpre. Vol. 94, Weekly Epidemiological Record = Relevé épidémiologique hebdomadaire. World Health Organization = Organisation mondiale de la Santé; 2019. p. 389-411.

5. Aisyah I, Agusni I. A retrospective study: Profile of new leprosy patients. Period Dermatol Venereol. 2018;30:40-7.

6. Martelli CM, de Maroja MF, Pardillo F, Stefani MM, Villahermosa L, Scollard DM, et al. Risk factors for leprosy reactions in three endemic countries. Am J Trop Med Hyg. 2015;92(1):108-14. http://doi.org/10.4269/ajtmh.13-021 PMid:25448239

7. Ranque $B$, Nguyen $V T$, Vu HT, Nguyen TH, Nguyen NB, Pham XK, et al. Age is an important risk factor for onset and sequelae of reversal reactions in Vietnamese patients with leprosy. Clin Infect Dis. 2007;44(1):33-40.

PMid:17143812

8. Stanojcic M, Chen P, Xiu F, Jeschke MG. Impaired immune response in elderly burn patients: New insights into the immunesenescence phenotype. Ann Surg. 2016;264(1):195-202. http:// doi.org/10.1097/SLA.0000000000001408

PMid:26649579

9. Morey JN, Boggero IA, Scott AB, Segerstrom SC. Current directions in stress and human immune function. Curr Opin Psychol. 2015;5:13-7. http://doi.org/10.1016/j. copsyc.2015.03.007

PMid:26086030

10. Lastória JC, de Abreu MA. Leprosy: Review of the epidemiological, clinical, and etiopathogenic aspects-part 1. An Bras Dermatol. 2014;89(2):205-18. http://doi.org/10.1590/ abd1806-4841.20142450

PMid:24770495

11. Rao PS, John AS. Nutritional status of leprosy patients in India. Indian J Lepr. 2012;84(1):17-22.

PMid:23077779

12. Ribeiro de Jesus A. Micronutrientes que influyen en la respuesta inmune en la lepra. Nutr Hosp. 2014;1:26-36.

13. Hungria EM, Oliveira RM, Penna GO, Aderaldo LC, de Pontes MA, Cruz R, et al. Can baseline ML Flow test results predict leprosy reactions? An investigation in a cohort of patients enrolled in the uniform multidrug therapy clinical trial for leprosy patients in Brazil. Infect Dis Poverty. 2016;5(1):110. http://doi. org/10.1186/s40249-016-0203-0

PMid:27919284

14. Antunes DE, Ferreira GP, Nicchio MV, Araujo S, da Cunha AC, Gomes RR, et al. Number of leprosy reactions during treatment: Clinical correlations and laboratory diagnosis. Rev Soc Bras Med Trop. 2016;49(6):741-5. http://doi. org/10.1590/0037-8682-0440-2015 PMid:28001221

15. Antunes DE, Araujo S, Ferreira GP, da Cunha AC, da Costa AV, Gonçalves MA, et al. Identification of clinical, epidemiological and laboratory risk factors for leprosy reactions during and after multidrug therapy. Mem Inst Oswaldo Cruz. 2013;108(7):901-8. http://doi.org/10.1590/0074-0276130222

PMid:24271045

16. de Brito MF, Ximenes RA, Gallo ME, Bührer-Sékula $S$. Association between leprosy reactions after treatment and bacterial load evaluated using anti PGL-I serology and bacilloscopy. Rev Soc Bras Med Trop. 2008;41(Suppl 2):67-72. http://doi.org/10.1590/s0037-86822008000700014 PMid: 19618079

17. Sousa AL, Stefani MM, Pereira GA, Costa MB, Rebello PF, Gomes MK, et al. Mycobacterium leprae DNA associated with Type 1 reactions in single lesion paucibacillary leprosy treated with single dose rifampin, ofloxacin, and minocycline. Am J Trop Med Hyg. 2007;77(5):829-33.

PMid:17984336

18. Fava VM, Manry J, Cobat A, Orlova M, Van Thuc N, Ba NN, et al. Amissense LRRK2 variant is a risk factor for excessive inflammatory responses in leprosy. PLoS Negl Trop Dis. 2016;10(2):e0004412. http://doi.org/10.1371/journal.pntd.0004412 PMid:26844546

19. Fischer M. Leprosy an overview of clinical features, diagnosis, and treatment: CME article. J Deutsch Dermatol Gesellschaft. 2017;15(8):801-27.

20. Spencer JS, Duthie MS, Geluk A, Balagon MF, Kim HJ, Wheat $\mathrm{WH}$, et al. Identification of serological biomarkers of infection, disease progression and treatment efficacy for leprosy. Mem Inst Oswaldo Cruz. 2012;107 Suppl 1:79-89.

PMid:23283458

21. Oertelt-Prigione S. Immunology and the menstrual cycle. Autoimmun Rev. 2012;11(6-7):A486-92. http://doi.org/10.1016/j. autrev.2011.11.023

PMid:22155200 